\title{
PUKAKI EARTHQUAKE OF 17 DECEMBER 1978
}

\author{
I.M. Calhaem*
}

\section{INTRODUCTION}

Lake Pukaki is a natural lake but has been raised twice to provide water storage for power stations constructed or planned for the Upper and Middle Waitaki Hydro Schemes. The lake was first raised 9 metres in. 1955 to give a depth of 71.5 metres and a volume of about $5 \times 10^{9} \mathrm{~m}^{3}$. A second dam, the Pukaki High Dam, was completed in 1978 to raise the lake a further 37 metres and add $5.5 \times 10^{9} \mathrm{~m}^{3}$ to the volume. This will create a lake with a maximum depth of 108 metres and a volume of more than $10 \times 10^{9} \mathrm{~m}^{3}$.

In accordance with the recommendation of the 'UNESCO Working Group on Seismic Phenomena Associated with Large Reservoirs' (Adams et al, 1973(1)), the New Zealand Electricity Division of the Ministry of Energy installed a seismic network around Lake Pukaki comprising 8 vertical and 1 three-component seismometers. This has been operating continuously since June 1975.

\section{SEISMIC EFFECTS OF LARGE RESERVOIRS}

In recent years a number of dams have beeñ instrumented after impounding but few have been fully instrumented prior to filling. Most reservoirs which have been associated with known seismic effects have had a depth greater than 100 metres or a volume exceeding $2 \times 10^{9} \mathrm{~m}^{3}$.

Both these parameters will be exceeded at Lake Pukaki, but as the filling has been accomplished over a number of years and at discrete epochs, the possible seismic effects of impounding the Pukaki High Dam are unknown.

Analysis of known reservoir induced seismicity (Gupta $1976(2)$ ) has shown that the seismif activity tends to follow Mogi's (1963(3)) Type 2 foreshock-aftershock pattern (figure 1), presumably because of the nonuniform stress field created in the vicinity of the reservoir.

Gupta $\left(1976^{(2)}\right.$ ) also suggests that the ' $b$ value' of induced seismicity is higher than for normal earthquake sequences in a region, that the magnitude difference between the largest after-shock and the main shock is small (0.6), and that the aftershocks have a comparatively slow rate of decay. Not all of these effects can be assessed in the case of Lake Pukaki because of the normally low seismic activity of the region.

In a number of cases the rate of induced seismicity has been found to follow changes in lake level. A detailed analysis of the activity associated with the impounding

* Seismological Observatory, Geophysics Div., D.S.I.R., Wellington. of the Koyna Dam has shown that the rapid rise in lake level following each spring flood was followed by an increase in seismic activity. However the activity decreased from year to year, and it has been suggested that this could provide a means of controlling the release of energy. If a reservoir was impounded slowly, with a pause whenever the seismic activity increased, the energy might be released as a number of small events rather than one large one.

\section{BACKGROUND SEISMICITY OF THE PUKAKI REGION}

Since June 1975 a high gain seismic network has been operating around Lake pukaki. The network forms an array about $70 \mathrm{~km}$ north-south and $50 \mathrm{~km}$ east-west with each station transmitting continuous seismic information to a central station at the Twizel Control Centre, where the signals are recorded on microfilm, together with accurate time signals. The three component station is at TMP (figure 2) and all instruments are $1 \mathrm{~Hz}$ Mark products L4-C seismometers with a peak recording magnification of $1,750,000$ at $10 \mathrm{~Hz}$.

Because of the extent and high magnification of the network many events have been recorded, but only those in the immediate vicinity of the network have been routinely analysed. They include events on the Alpine Divide and to the south of Lake Benmore, which are most unlikely to have any connection with Lake Pukaki. Therefore only events located within $40 \mathrm{~km}$ of Lake Pukaki have been considered in the following discussion. The magnitudes of events determined by the Pukaki Network are determined from an empirical formula. Although internally consistent, these magnitudes cannot be directly related to those determined by the New Zealand Network because events recorded at Pukaki are usually either too small to be recorded elsewhere, or so large that the Pukaki instruments are overloaded. Where events have been recorded well on the New Zealand network a local magnitude $\left(M_{L}\right)$ has been assigned.

The time distribution of earthquakes close to Lake Pukaki is shown in figure 3 (c) and the energy in figure $3(d)$. The monthly average is $7 \pm 5$ earthquakes per month with peaks occurring in April 1977 (2l events) and August 1978 (29 events). A magnitude 2.5 earthquake in June 1976 occurred west of Lake Benmore and was the largest event recorded in the vicinity of lake Pukaki during the first three and a half years of recording. This event produced a peak in the energy graph (figure $3(d)$ ), but because there were few aftershocks there is no corresponding peak in the number of earthquakes. Indeed the seismic activity of this region is characterised by small, 
seemingly unrelated events. All earthquakes have been shallow with most being located between 5 and $10 \mathrm{~km}$ deep.

\section{SEISMIC ACTIVITY IN DECEMBER 1978}

On 17th December 1978 an earthquake of magnitude $M_{T}=4.6$ occurred at $44.139 \mathrm{~S}$ $170.06 \mathrm{E}$ and $4 \pm 2 \mathrm{~km}$ deep, $10 \mathrm{~km}$ northwest of the Pukaki High Dam. This earthquake was preceded by 8 foreshocks starting 3 days before; 5 of the foreshocks were within 16 minutes of the main event, with the largest, a magnitude $\mathrm{M}_{\mathrm{L}}=2.8$, occurring 8 minutes before.

A well defined aftershock sequence followed the main shock with nearly 400 aftershocks occurring in the first 24 hours. The magnitude-frequency relationship is shown in figure 4. It does not follow the classical linear relationship $\log \mathrm{N}=1-\mathrm{bM}$ and suggests a lack of events greater than magnitude 1. For magnitudes between -1 and 1 the $b$ value is 0.6 , but for higher magnitudes the $\mathrm{b}$ value is approximately 1.5 . Gupta (1976(2)) suggests that a high value is characteristic of reservoir induced seismicity, but the small number of events greater than magnitude 1.0 leaves the present case open to speculation.

The magnitude distribution of the aftershocks does not follow either the relationship proposed by Bath (1965(4)) for normal large shallow earthquakes $\left(\mathrm{M}_{0}-\mathrm{M}_{1}=\overline{\overline{5}} 1.2\right)$, or that proposed by papazachos $\left(197 \frac{1}{4}(\overline{5})\right.$ ) for reservoir induced earthquake sequences $\left(M_{0}-M_{1}=0.6\right)$, where $M_{0}$ is the magnitude of the main shock and $M_{1}$ that of the largest aftershock. In the present aftershock sequence the relation is

$M_{0}-M_{1}=2.0$

reflecting the lack of large events in the aftershock sequence.

The rate of decay of the aftershock sequence is shown in figure 5 and obeys the following relationship

$n(t)=125 t^{-1.2}$

This is somewhat faster than the decay observed in other reservoir induced sequences but follows the same relationship.

The first motions of the main event are plotted in figure 6. The foreshocks and aftershocks follow the same pattern with the exception of the readings at MMP, where some aftershocks show compression and others dilation. Since all other first motions are consistent, it appears that small changes in epicentral position are sufficient to move the nodal plane from one side of this station to the other.

The pattern of first motions is consistent with sinistral strike-slip movement on a northsouth fault and it is possible that the earthquake occurred on the Ostler fault (figure 2). This is supported by the long period records from horizontal seismographs at Roxburgh, about $140 \mathrm{~km}$ SSw of the epicentre, which show most energy in a north-south direction. and by anomalously low amplitudes recorded at RHP, the station nearest to the epicentre. If the motion was predominantly strike-slip then very little vertical movement would be expected at a station almost at the epicentre.

The seismic energy released in December 1978 is more than 600 times the total energy released in the previous three and a half years (figure $3(d)$ ) and occurred at a time when Lake Pukaki was filling rapidly. Previous peaks in the number of earthquakes (April 1977 and August 1978) also occurred after rapid filling, but the lake was less full and there was only a slight increase in the energy released.

\section{SUMMARY}

The seismic activity in December 1978 is different in character from that observed during the previous three and a half years. No other events have been accompanied by both foreshocks and aftershocks, and the seismic energy is significantly greater than at any previous time. Since the activity occurred at a time when the lake was filling rapidly it appears possible that the activity could be reservoir induced. If this is so then the earlier peaks of April 1977 and August 1978 might also be the result of rapid changes in lake level. on both these occasions the activity returned to normal within one month, but it is noted that whilst the lake level had changed rapidly prior to the activity, it did not change thereafter (figure $3(a)$ ), and perhaps this helped the return to normal.

\section{REFERENCES}

1. Adams, R. D., Gough, D. I., and Muirhead, K. J., 1973. "Seismic Surveillance of Artificial Reservoirs". UNESCO Working Group on Seismic Phenomena Associated with Large Reservoirs, Annexure 1, Rep. 3rd Meet., March 1973, London.

2. Gupta, H. K., and Rastogi, B.K., 1976. "Dams and Earthquakes". Developments in Geotechnical Engineering, 11. Elsevier Scientific Publishing Co., Amsterdam.

3. Mogi, K., 1963. "Some Discussions on Aftershocks, Foreshocks and Earthquake Swarms - the Fracture of a Seimi-Infinite Body Caused by an Inner Stress Origin and its Relation to the Earthquake Phenomena" (third paper). Bull. Earthquake Res. Inst., 4l: 615-658.

4. Bath, M., 1965. "Lateral Inhomogeneities in the Upper Mantle". Tectonophysics, 2: 483-515.

5. Papazachos, B.C., 1974. "On the Relation Between Certain Artificial Lakes and the Associated Seismic Sequences". Paper presented at Int. Colloq. on seismic Effects of Reservoir Impounding, the Royal Society, London, March 1973.

Paper Received 6 March, 1979. 


$$
\left\{\begin{array}{c}
\text { Structure } \\
\text { of Material }
\end{array}\right\} \quad\left\{\begin{array}{l}
\text { Distribution of } \\
\text { External Stress }
\end{array}\right\}
$$

Main Shock

TYPE 1

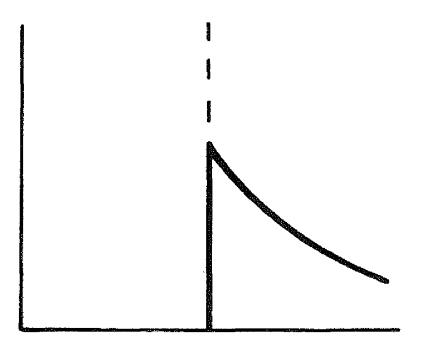

Homogeneous

Main Shock

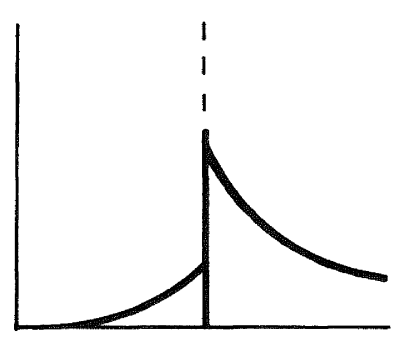

Heterogeneous in

some degree

TYPE 2

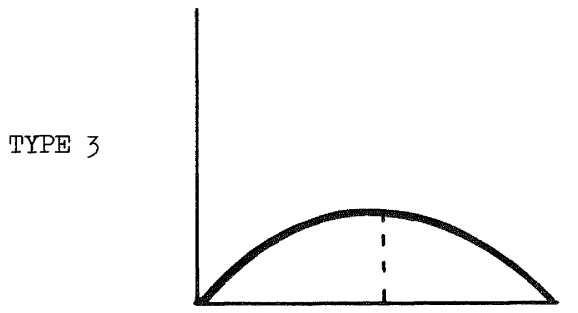

Ex.tremely

Heterogeneous

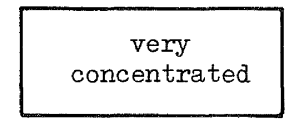

FIGURE 1: FORESHOCK - AFTERSHOCK PATTERNS AND THEIR RELATIONSHIP TO THE STRUCTURE OF MATERIALS AND APPLIED STRESSES. (THE VERTICAL AXIS IS THE FREQUENCY OF EARTHQUAKES AND THE HORIZONTAL AXIS IS TIME).

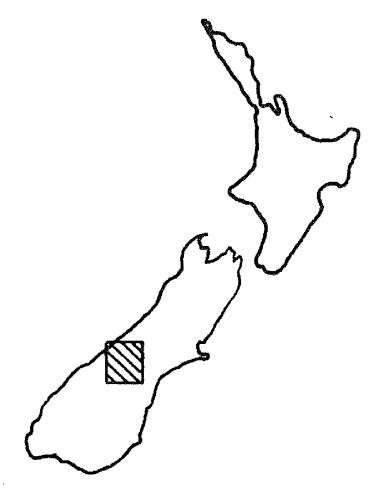

HGP •
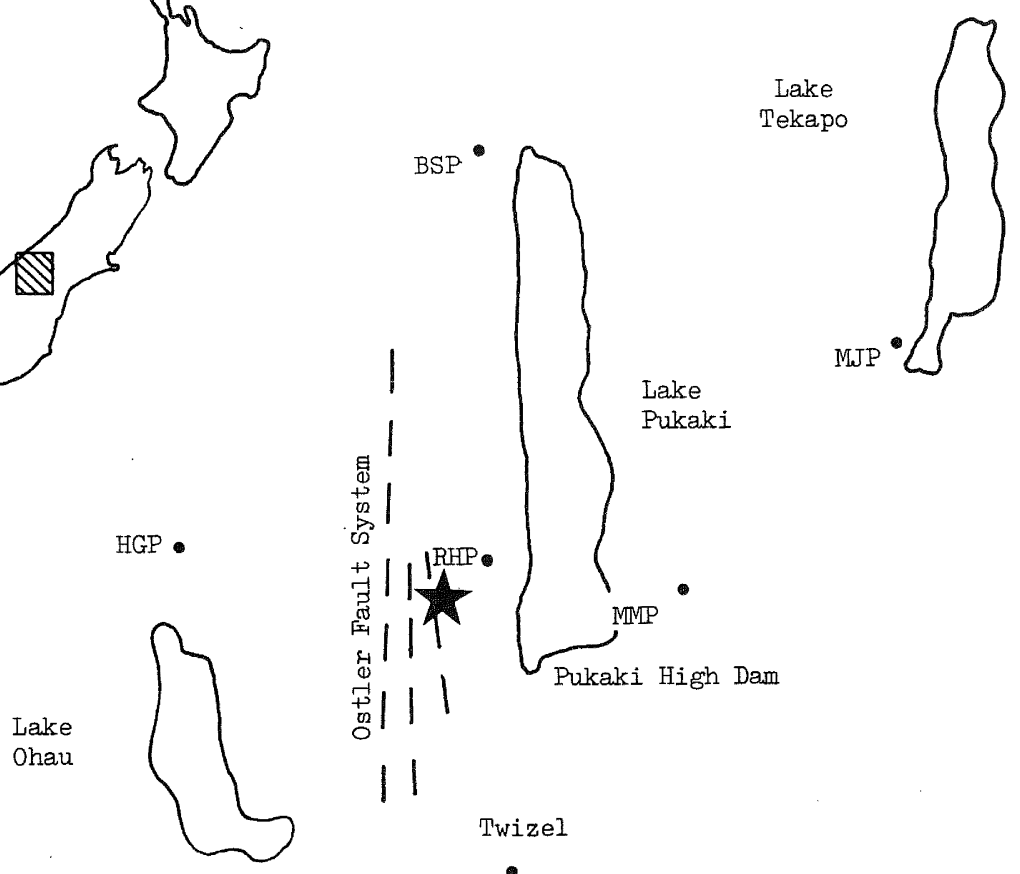

DMP.

THP •

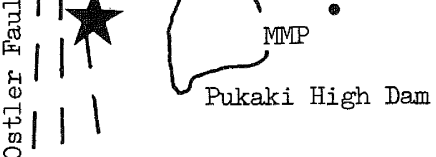

11

Twizel

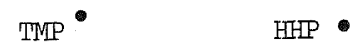

Lake

Benmore

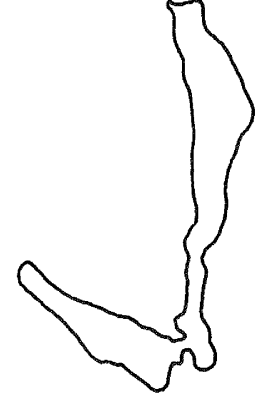

PP

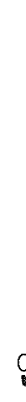

$\mathrm{km}$

FIGURE 2: PUKAKI SEISMIC NETWORK AND LOCATION OF MAIN EARTHQUAKE OF 17TH DECEMBER 1978 


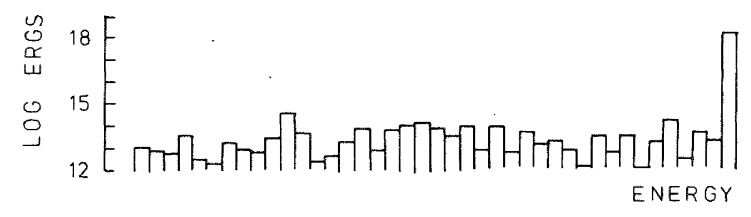

竞:
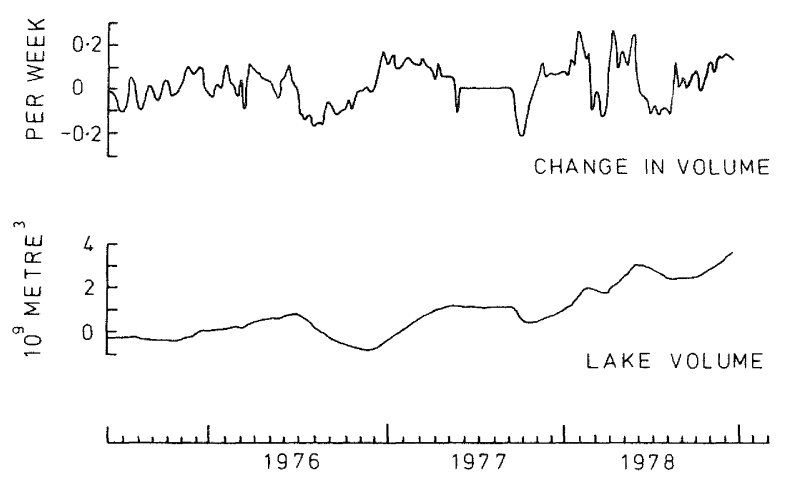

FIGURE 3: EARTHOUAKE ACTIVITY NEAR PUKAKI DAM DURING LAKE FILLING

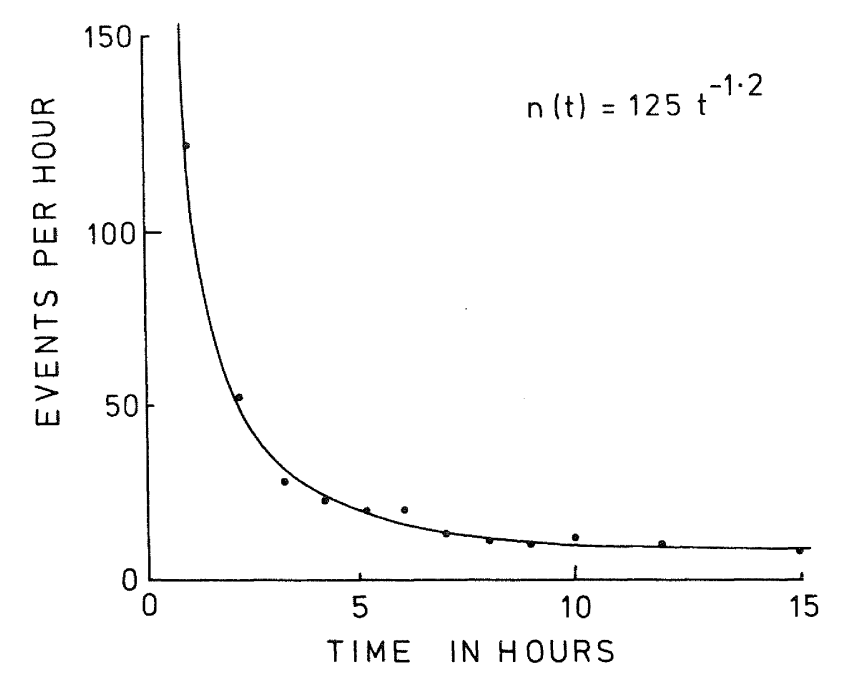

FIGURE 5: DECAY OF THE FREQUENCY OF AFTERSHOCKS AFTER THE MAIN EVENT

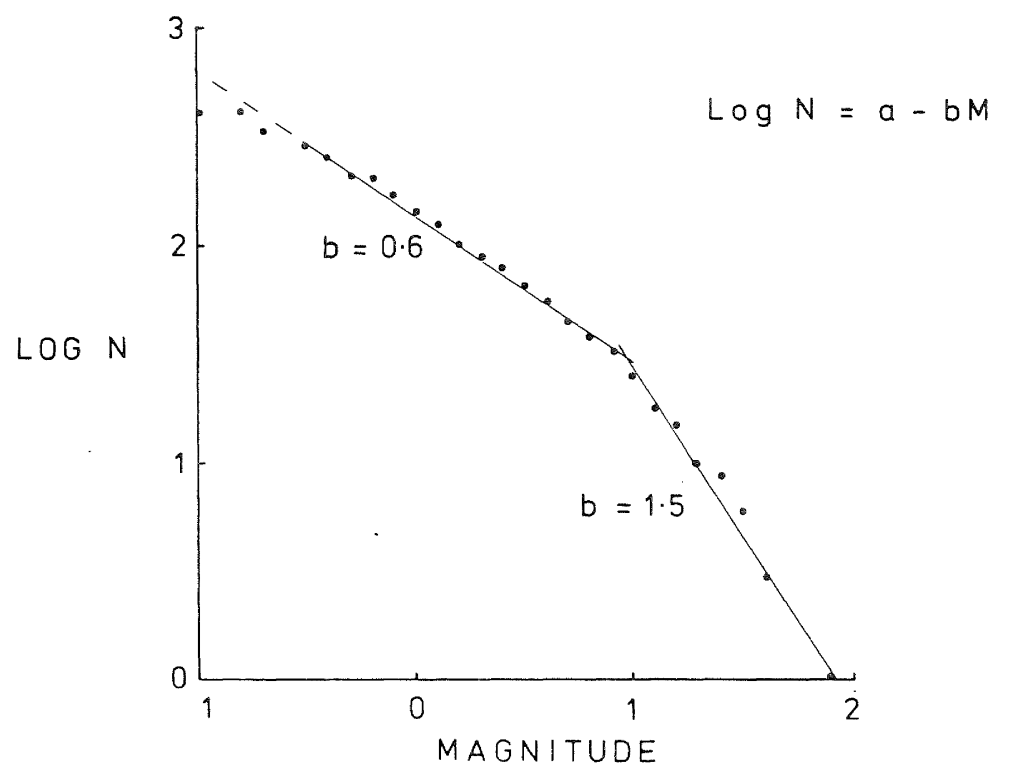

FIGURE 4: FREQUENCY MAGNITUDE RELATIONSHIPS FOR AFTERSHOCKS

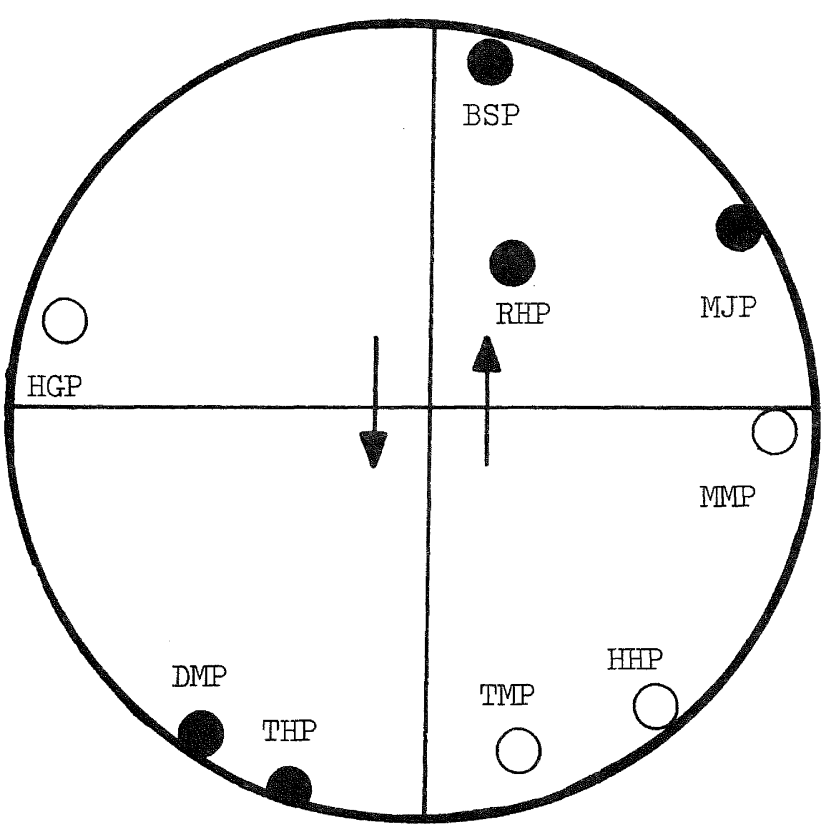

UPPER HEMISPHERE PLOT

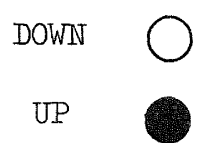

FIGURE 6: FAULT PLANE SOLUTION FOR THE MAIN EVENT (THE DIAGRAM ILLUSTRATES LIKELY SINISTRAL STRIKE SLIP MOVEMENT ON A NORTH SOUTH FAULT - SEE FIGURE 2). 